\title{
Strength prediction of Class G oilwell cement during early ages by electrical conductivity
}

\author{
Syahrir Ridha $\cdot$ Sonny Irawan $\cdot$ Bambang Ariwahjoedi
}

Received: 10 May 2012/ Accepted: 28 August 2013/Published online: 8 September 2013

(C) The Author(s) 2013. This article is published with open access at Springerlink.com

\begin{abstract}
The compressive strength of oilwell cement plays an important role in securing the long-term integrity of wellbore. The cement's strength development is experimentally difficult to perform once the cement has been displaced into the wellbore. Failure to monitor its development especially during early hydration may lead to secondary cementing operation or in the worst case may damage the well. This paper proposes an empirical equation for strength prediction of Class $\mathrm{G}$ oilwell cement using electrical conductivity at elevated pressure up to $3,000 \mathrm{psi}$ and temperature up to $65{ }^{\circ} \mathrm{C}$ during the first $24 \mathrm{~h}$ of hydration. The study used both porosity-strength correlations and strength-electrical properties relationship to produce predictive equation for strength of oilwell cement. The proposed equation was experimentally compared to cement samples with different water-cement ratios and curing conditions to validate the result. A good agreement is achieved between the proposed equation and the measured data. Furthermore, the strength up to 50 days can be predicted by the proposed equation.
\end{abstract}

Keywords Electrical conductivity $\cdot$ Compressive strength $\cdot$ Porosity $\cdot$ Elevated conditions

\footnotetext{
S. Ridha $(\bowtie) \cdot S$. Irawan

Department of Petroleum Engineering, Universiti Teknologi

PETRONAS, Seri Iskandar, Malaysia

e-mail: syahrir.ridha@petronas.com.my

B. Ariwahjoedi

Department of Fundamental and Applied Sciences, Universiti

Teknologi PETRONAS, Seri Iskandar, Malaysia
}

\section{Introduction}

In cementing operation, certain minimum strength of about $500 \mathrm{psi}$ is required before restarting the drilling operations (Backe et al. 2001). This waiting strength is called as waiton-cement (WOC), which is dependent on the hydration time. It is directly related to the drilling cost per hour with a longer waiting time which will pose extra cost, and shorter waiting time may contribute to cement failure due to imperfect setting time of cement.

Typically, the WOC during a cementing operation could range from a few hours to several days, depending on the difficulty of the cement job. Prior to that, a regular cement bond log may result in a pessimistic interpretation. Hence, an accurate evaluation and estimation on appropriate cement strength becomes considerably important to reduce cost expenditure, particularly at the early ages when the physical and mechanical properties of well cement significantly change with times.

In the literature, it is found that the influence of porosity on the strength of cement has already been well recorded in many models such as Balshin (1949), Hasselman and Fulrath (1964), Ryshkewitch (1953) and Schiller (1971). These models have been applied using a measured porosity and relating it to its strength; this is rather impractical for the oilfield used. Therefore, a simple correlation becomes necessary. Although the correlations between porosity and strength for several engineering materials have been intensively investigated, its pertinence to the Class G oilwell cement under elevated conditions still needs to be carefully examined.

An electrical conductivity technique has been rapidly developed and widely applied in composite material characterization, in particular to the cement-based system. Many attempts have been made to investigate the 
microstructural properties of the cement system for certain purposes in construction such as building, road and bridge. However, its application into oilwell cement still has less attention, especially during early hydration (Gu et al. 1993; Christensen et al. 1994; Mindess et al. 2003; Rajabipour and Weiss 2007; Zhang et al. 2009; Neithalath et al. 2011). Therefore, this emerging technique of electrical conductivity is applied as a tool to predict cement strength based on its porosity and normalized conductivity by including the effect of elevated pressure and temperature. The quantitative relationship between electrical conductivity and strength of oilwell cement becomes the objective of this paper.

\section{Experimental method}

Five batches of cement slurry were mixed with tap water at water-cement ratios (w/c) of $0.55,0.5,0.4,0.3$ and 0.25 . In this case, some samples with w/c of 0.25 and 0.55 acted as a controller variable. In this study, API cement Class G High Sulfate Resistant (G-HSR) with the specific gravity of $3.2 \mathrm{~g} / \mathrm{cm}^{3}$ obtained from LaFarge Malaysia was used. Table 1 presents the composition of the cement measured by X-ray fluorescence analysis.

Referring to the recommended practice of API 10A (2002), the composition, subsequently, was mixed at a constant speed at $4,000 \mathrm{rpm}$ for $30 \mathrm{~min}$ in which the cement powder was gently poured into the mixer that had been filled with water until well mixed. The mixing process was continued by increasing the speed of mixing up to $12,000 \mathrm{rpm}$ for $35 \mathrm{~min}$. Having been prepared, the cement slurry was immediately placed into a 1-inch diameter $\times 1$-inch length cylinder rubber jacket for the impedance measurement. Afterward, the sample was weighed using a digital balance in which the weight measurement was used as an input in the electrical conductivity measurement.

Table 1 Composition of Class G-HSR cement

\begin{tabular}{lclc}
\hline $\mathrm{Raw}$ oxide & Wt. $\%$ & Bogue phases $^{\text {a }}$ & Wt. \% \\
\hline $\mathrm{CaO}$ & 64.3 & $\mathrm{C}_{3} \mathrm{~S}$ (tricalcium silicate) & 62.5 \\
$\mathrm{SiO}_{2}$ & 21.2 & $\mathrm{C}_{2} \mathrm{~S}$ (dicalcium silicate) & 9.3 \\
$\mathrm{Al}_{2} \mathrm{O}_{3}$ & 3.8 & $\mathrm{C}_{3} \mathrm{~A}$ (tricalcium aluminate) & 2 \\
$\mathrm{Fe}_{2} \mathrm{O}_{3}$ & 4.76 & $\mathrm{C}_{4} \mathrm{AF}$ (tetracalcium aluminoferrite) & 14.5 \\
$\mathrm{SO}_{3}$ & 2.61 & & \\
$\mathrm{MgO}$ & 2.3 & & \\
$\mathrm{~K}_{2} \mathrm{O}$ & 0.32 & & \\
$\mathrm{Na}_{2} \mathrm{O}$ & 0.46 & &
\end{tabular}

a Cement chemistry notation: $C \mathrm{CaO}, \mathrm{S} \mathrm{SiO}_{2}, A \mathrm{Al}_{2} \mathrm{O}_{3}, F \mathrm{Fe}_{2} \mathrm{O}_{3}$

\section{Electrical conductivity}

Electrical conductivity information was obtained using Core Test System Auto Lab from New England Research. Figure 1 depicts a schematic diagram of electrical impedance measurement Autolab-500 manual book (2007). The mixed cement samples were placed in accordance with the core holder apparatus. Prior to installing the apparatus, the cement samples were firstly jacketed by a flexible rubber to avoid leakage or fluid loss. To measure electrical properties, the electrode was carefully aligned with each end of the sample. The standardized electrode materials consisting of porous silver membrane filters produced by Osmonics Inc. were used here.

The execution of the electrical measurement using fourelectrode configurations was purposely to minimize the effect of electrode polarization (Ford et al. 1995). Here, the frequency of measurement, totally involving 25 data points of frequencies for each execution stored, was set from $0.2 \mathrm{MHz}$ to $1 \mathrm{~Hz}$ in a logarithmic sweep. These measurements were performed repeatedly until the sample reached

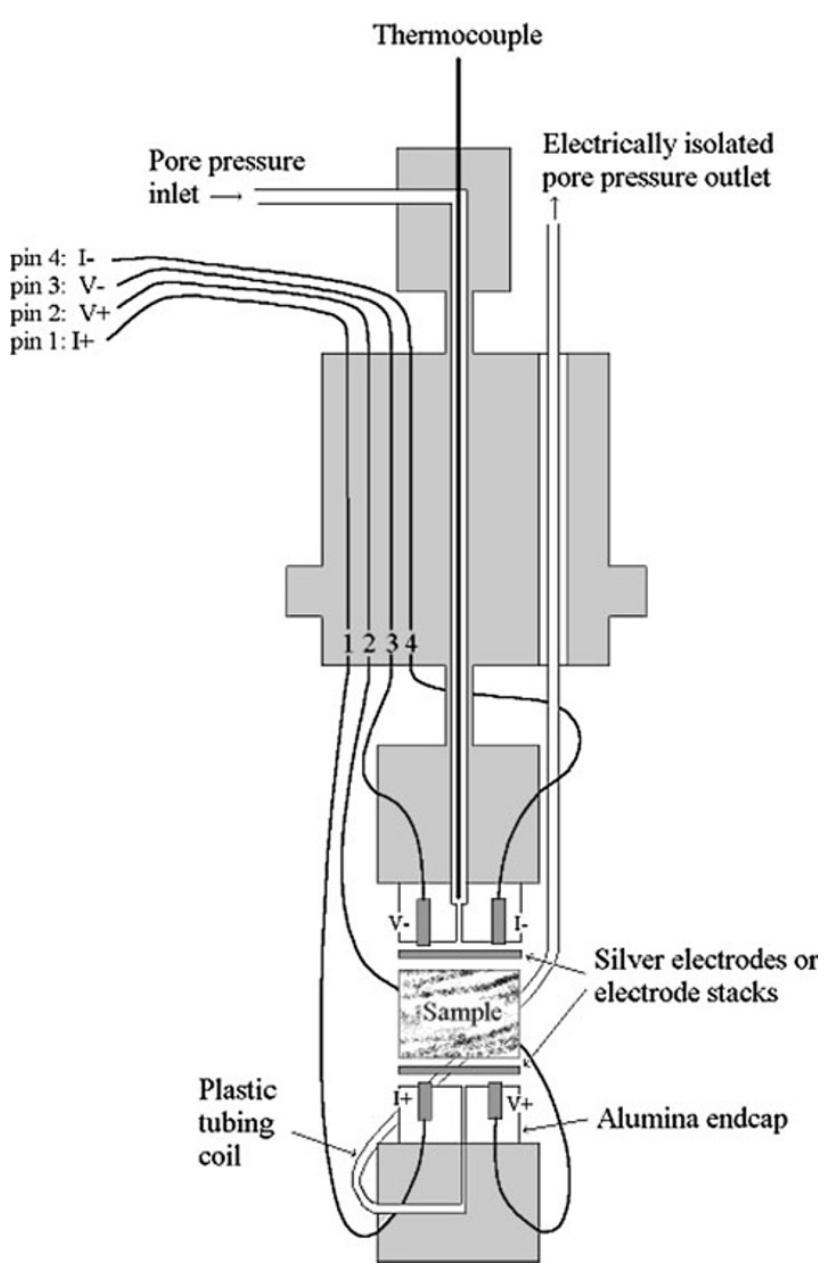

Fig. 1 Schematic of core holder in the CoreTestSystem ${ }^{\mathrm{TM}}$ 
Table 2 Measurement scenarios for conductivity measurement

\begin{tabular}{lllc}
\hline Sample no. & w/c & Temp. $\left({ }^{\circ} \mathrm{C}\right)$ & Pres. $(\mathrm{psi})$ \\
\hline 1 & 0.25 & 70 & 3,000 \\
2 & 0.3 & 25 & 14.7 \\
3 & 0.3 & 40 & 1,500 \\
4 & 0.3 & 65 & 3,000 \\
5 & 0.4 & 25 & 14.7 \\
6 & 0.4 & 40 & 1,500 \\
7 & 0.4 & 65 & 3,000 \\
8 & 0.5 & 25 & 14.7 \\
9 & 0.5 & 40 & 1,500 \\
10 & 0.5 & 65 & 3,000 \\
11 & 0.55 & 70 & 3,000 \\
\hline
\end{tabular}

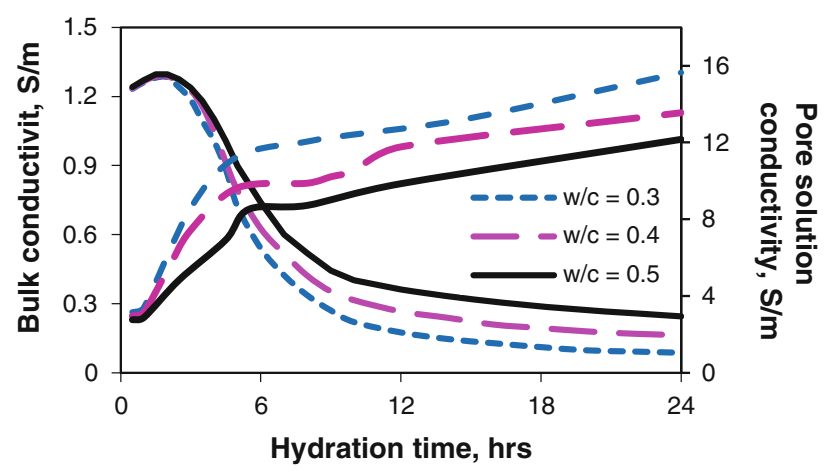

Fig. 2 Bulk and pore solution conductivity at atmospheric conditions as a function of hydration time

$24 \mathrm{~h}$ of hydration. Table 2 presents the scenarios of the measurements that illustrate the wellbore conditions during cementing operation starting at ambient condition to gradually achieve elevated temperature and pressure.

The confining pressure of 3,000 psi, on the other hand, was manually conditioned using a hydraulic pump. The output from the measurement system subsequently was recorded by the data acquisition system. The system temperature of about $65^{\circ} \mathrm{C}$ was then obtained by heating the oil chamber and recorded by an integrated thermocouple of the system. Measurements were gradually collected at several 30-min intervals for the first $5 \mathrm{~h}$, followed by the 1-hour increment for the next measurement up to $10 \mathrm{~h}$ and continued at the 2-hour interval until reaching $24 \mathrm{~h}$ of hydration. Figure 2 presents some results of the conductivity properties measurements.

\section{Porosity}

Pascal 240 and 440 high-pressure porosimeters were used in this study to quantify the porosity of well cement during hydration based on the capillary law governing liquid penetration into small pores as functions of surface and interfacial liquid tensions, pore-throat size and shape, and wetting properties of sample. This can be expressed in the following form by Washburn (1921):

$P_{c}=-\frac{2 \gamma \cos \theta}{r}$

where $P_{c}$ is the capillary pressure $\left(\right.$ dynes $\left./ \mathrm{cm}^{2}\right), \gamma$ the surface tension of $\mathrm{Hg}$ (489 dyne/cm), $\theta$ the contact angle between mercury and cement pore wall $\left[140^{\circ}\right.$ was assumed (Christensen et al. 1996)], and $r$ is the radius of pore-throat aperture for a cylindrical pore $(\mathrm{cm})$.

Before measuring the porosity, the cement hydration of all samples were ceased by applying a solvent exchange procedure that was by replacing water inside the cement samples as suggested by Zhang et al. (2009). For samples at atmospheric condition, placing those samples into 1 inch $\times 1$ inch cylinder rubber jacket was the curing process. Another sample conditioning was performed in the HPHT curing chamber containing a sample cell with a dimension of 1 inch $\times 1$ inch $\times 1$ inch. The curing durations were set to around 5, 10, 16 and $24 \mathrm{~h}$ for each scheduled samples. The samples for each curing period of about 4-8 g were rinsed in a 100-ml acetone in the sealable container and shaken vigorously. The solvent was renewed regularly 2-3 times during the first $24 \mathrm{~h}$ and repeated about once per day for the rest 2 days. After soaking in acetone and before conducting porosity measurement, the samples were placed into a drying oven at $80^{\circ} \mathrm{C}$ for $24 \mathrm{~h}$. Three measurements were made for each sample condition to ensure data reproducibility, and by averaging these measurements, the final result was then calculated.

\section{Compressive strength}

The compressive strength development of all samples of a 24-h hydration was monitored using Ultrasonic Cement Analyzer (UCA). This device works based on the transmission characteristics of an ultrasonic compressional wave through cement slurry. It was done by an analyzer by measuring the transit time and converting it to apparent and compressive strength. The widespread use and acceptance of the UCA made it to be accepted as a recommended practice for determining sonic strength in API RP 10 B-2 (2005). In this study, the Model 200 UCA from Cement Test Equipment ${ }^{\odot}$ was used.

Directly after mixing, the sample was placed in the test cell until the proper fill level was obtained using the slurry level gauge. Extra water was added until reaching the water fill line on the slurry level gauge. The measurement was performed for $24 \mathrm{~h}$ of hydration and the maximum pressure and temperature for setting were $3,000 \mathrm{psi}$ and $65^{\circ} \mathrm{C}$, subjected to the same conditions as mentioned in Table 2 . 
Existing models for cement-based material

To relate the electrical conductivity to compressive strength, it is worth noting that the correlations between porosity and compressive strength for several engineering materials have been intensively investigated (Balshin 1949; Hasselman and Fulrath 1964; Ryshkewitch 1953; Schiller 1971). However, its pertinence to the Class $\mathrm{G}$ oilwell cement under an elevated condition still needs to be examined.

Balshin has suggested the following power law correlation for powder metal ceramic:

$S=S_{0}(1-\phi)^{b}$

where $S$ is the strength, $S_{0}$ the strength at zero porosity, $\phi$ the porosity, and $b$ is the empirical constant.

Meanwhile, Hasselman proposed a linear relationship between strength and porosity for different refractory glass materials.

$S=S_{0}-b \phi$

where $S$ is the strength, $S_{0}$ the strength at zero porosity, $\phi$ the porosity, and $b$ is the empirical constant.

Schiller also suggested a logarithmic correlation between strength and porosity for gypsum paste or nonmetallic brittle materials.

$S=b \ln \frac{\phi_{0}}{\phi}$

where $S$ is the strength, $\phi_{0}$ the porosity at zero strength, $\phi$ the porosity, and $b$ is the empirical constant.

Ryshkewitch introduced an exponential equation for porous sintered alumina and zirconia in relating strength and porosity.

$S=S_{0} e^{-b \phi}$

where $S$ is the strength, $S_{0}$ the strength at zero porosity, $\phi$ the porosity, and $b$ is the empirical constant.
To fit these models, an experimental study was made and used as a basis in predicting the strength using measured electrical conductivity for oilwell cement at an elevated pressure and temperature.

\section{Results and discussions}

Porosity-strength models evaluation

The evaluation was made by correlating both measured porosity and compressive strength of oilwell cement at different curing conditions and water to cement ratios. Data of measured porosity and strength are shown in Tables 3 and 4, and some results in the graphical form of strength measurement are displayed in Fig. 3. The measured porosity up to $24 \mathrm{~h}$ of hydration is in line with the result suggested by Justnes et al. (1995) with slight discrepancies due to the differences in the treatment of samples. The relationship between strength and porosity shows that a linear function has been produced between porosity and strength as shown in Fig. 4. The result of linear equations follows Eq. (3), respectively.

From Fig. 4, it can be seen that the fitted linear curve has yielded the equation $S=S_{0}-b \phi$ for which the values of $S_{o}$ and $b$ for w/c $0.5,0.4$ and 0.3 are: $S=5,899-$ $9,574(\phi)$ with an $R^{2}$ value of $0.989, \quad S=6,069-$ $10,316(\phi)$, with an $R^{2}$ value of 0.985 , and $S=6$, $812-14,192(\phi)$, with an $R^{2}$ of 0.987 . It is also noticed that the value of empirical parameters for maximum strength, $S_{0}$, was relatively similar irrespective of w/c ratios and reflected an intrinsic property of the hydration products. However, the maximum strength constant tended to increase as water-cement ratios increased. The values were in the range of 5,899-6,812 psi with an average approximation of 6,355 psi. It is mentioned that value in the
Table 3 Measured porosity of Class $\mathrm{G}$ cement at various curing conditions from MIP test

\begin{tabular}{lclll}
\hline $\begin{array}{l}\text { Temperature and } \\
\text { pressure }\end{array}$ & $\begin{array}{l}\text { Hydration } \\
\text { time }(\mathrm{h})\end{array}$ & $\begin{array}{l}\text { Porosity } \\
(\mathrm{w} / \mathrm{c}=0.5)\end{array}$ & $\begin{array}{l}\text { Porosity } \\
(\mathrm{w} / \mathrm{c}=0.4)\end{array}$ & $\begin{array}{l}\text { Porosity } \\
(\mathrm{w} / \mathrm{c}=0.3)\end{array}$ \\
\hline $25{ }^{\circ} \mathrm{C}$ and $14.7 \mathrm{psi}$ & 5 & 0.592 & 0.565 & 0.468 \\
& 10 & 0.556 & 0.514 & 0.416 \\
$40{ }^{\circ} \mathrm{C}$ and $1,500 \mathrm{psi}$ & 16 & 0.485 & 0.437 & 0.363 \\
& 24 & 0.455 & 0.401 & 0.321 \\
$65{ }^{\circ} \mathrm{C}$ and 3,000 psi & 5 & 0.579 & 0.545 & 0.442 \\
& 10 & 0.507 & 0.472 & 0.383 \\
& 16 & 0.432 & 0.422 & 0.331 \\
& 10 & 0.412 & 0.372 & 0.291 \\
& 16 & 0.562 & 0.532 & 0.424 \\
& 24 & 0.481 & 0.452 & 0.365 \\
\hline
\end{tabular}


Table 4 Measured strength of Class $\mathrm{G}$ cement at various curing conditions using UCA analysis

\begin{tabular}{lcccc}
\hline $\begin{array}{l}\text { Temperature and } \\
\text { pressure }\end{array}$ & $\begin{array}{l}\text { Hydration } \\
\text { time }(\mathrm{h})\end{array}$ & $\begin{array}{l}\text { Strength, } \\
\text { psi (w/c }=0.5)\end{array}$ & $\begin{array}{l}\text { Strength, } \\
\text { psi (w/c }=0.4)\end{array}$ & $\begin{array}{l}\text { Strength, } \\
\text { psi (w/c }=0.3)\end{array}$ \\
\hline $25{ }^{\circ} \mathrm{C}$ and 14.7 psi & 5 & 217 & 262 & 252 \\
& 10 & 712 & 847 & 914 \\
& 16 & 1,179 & 1,366 & 1,570 \\
$40{ }^{\circ} \mathrm{C}$ and $1,500 \mathrm{psi}$ & 24 & 1,572 & 1,759 & 2,086 \\
& 5 & 371 & 487 & 551 \\
$65{ }^{\circ} \mathrm{C}$ and 3,000 psi & 10 & 1,040 & 1,210 & 1,366 \\
& 16 & 1,703 & 1,771 & 1,997 \\
& 24 & 2,052 & 2,280 & 2,580 \\
& 10 & 469 & 542 & 763 \\
& 16 & 1,246 & 1,392 & 1,582 \\
& 24 & 1,841 & 2,036 & 2,341 \\
\hline
\end{tabular}

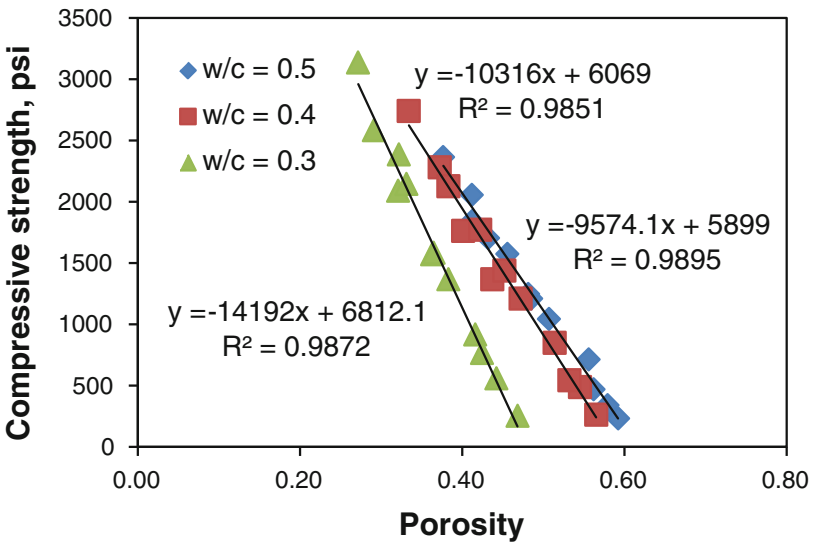

Fig. 3 Experimental data on porosity-strength linear relationship for Class $\mathrm{G}$ cement at different w/c ratios

literature was about 5,800 psi (Backe et al. 2001). The difference might be the various cement samples used and also sample curing conditions. The value of the empirical constant $b$ was in the range between 9,574 and 14,192, which increases as w/c ratios decreases, as expected.

The porosity-strength relationship from these results is taken as a basis for predicting the compressive strength from the measured normalized conductivity $\left(\sigma_{n}\right)$ using the porosity-electrical conductivity relations. As a result, once having been measured, the normalized conductivity on the Class G cement using the well-known Archie's law can be related to the porosity.

\section{Archie's porosity examination}

Archie's law has become the standard method for relating the conductivity of a clean reservoir rock to its porosity. In this study, it has been shown that Archie's equation can be used to estimate porosity of oilwell cement. The general
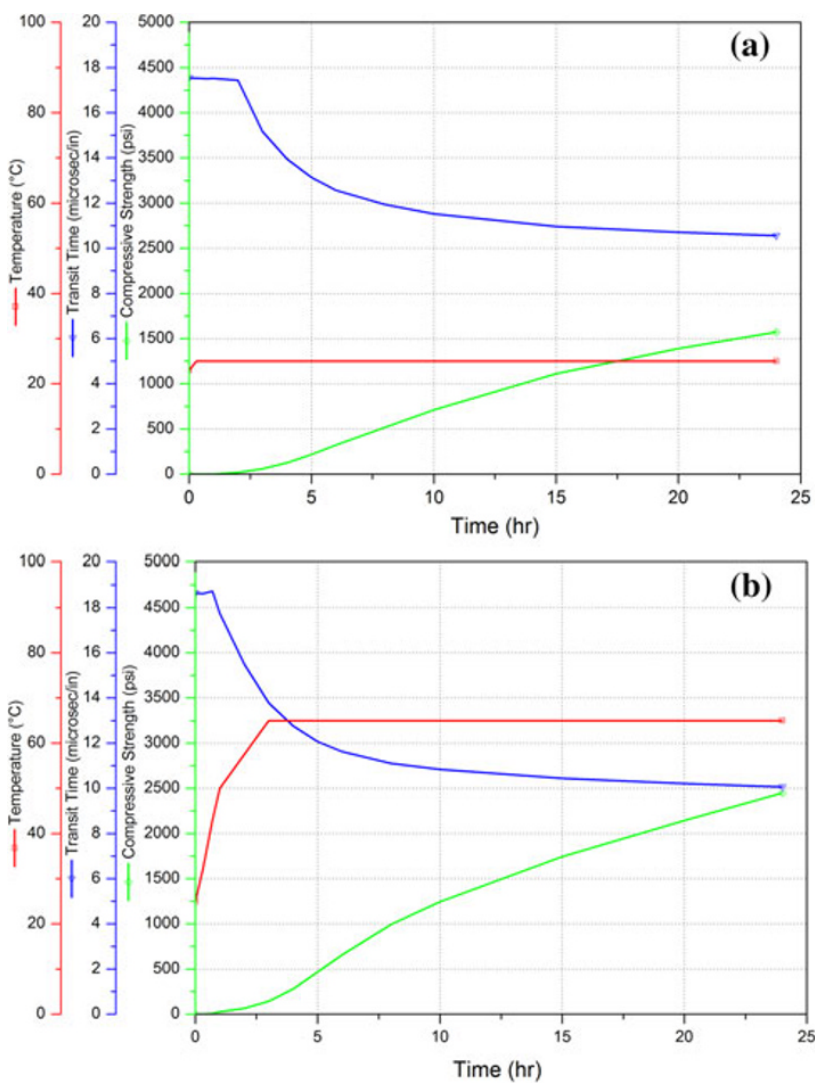

Fig. 4 Measured compressive strength of w/c 0.5 at a $25^{\circ} \mathrm{C}$ and 14.7 psi and $\mathbf{b} 65^{\circ} \mathrm{C}$ and 3,000 psi

form of Archie's law can be stated as follows (Archie 1942):

$\sigma_{b}=\sigma_{0} \phi^{m}$

where $\sigma_{b}$ is the bulk conductivity, $\sigma_{0}$ the pore solution conductivity, $\phi$ the porosity and $m$ is the cementation factor. 
It was shown that Archie's law included a variable term describing the connectivity of the conducting phase (cementation factor). Ewing and Hunt (2006) stated that Archie's law has a theoretical foundation as it can be derived by applying continuum percolation theory to fractal porous media. Furthermore, a reasonable physical phenomenon at the elevated temperature could be explained by Archie's model by the cementation exponent profile (Glover 2009).

The experimental results between normalized conductivity and porosity corresponding to Archie's model in the form of power law are shown in Fig. 5. The cementation factor in the equations was found to be varied referring to water-cement ratios and curing conditions. The larger it
Fig. 5 Normalized conductivity versus porosity for Class $\mathrm{G}$ cement of w/c 0.4 a $25^{\circ} \mathrm{C}$ and 14.7 psi and b $65^{\circ} \mathrm{C}$ and $3,000 \mathrm{psi}$
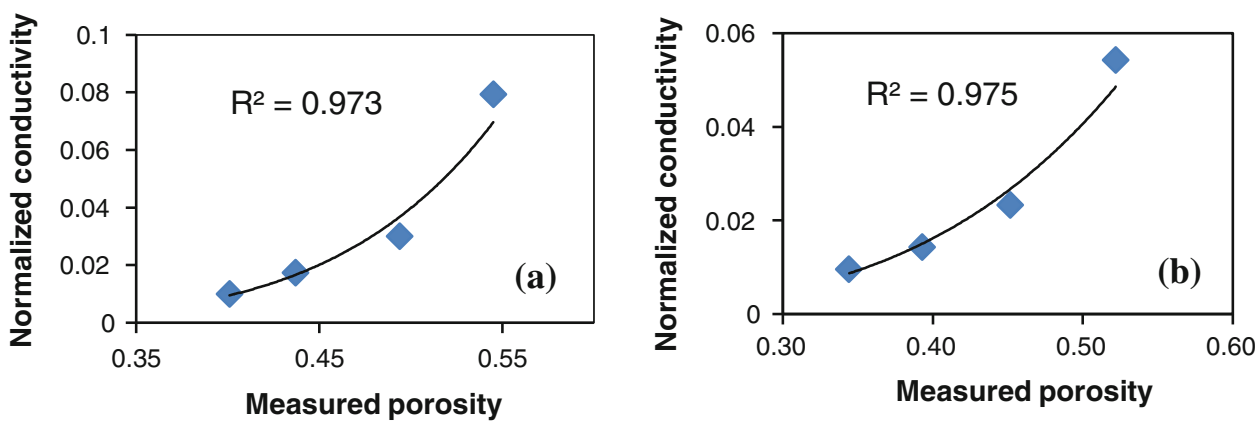

Fig. 6 Microstructure parameters distribution from fitting procedure between Archie's model and experimental measurements for Class $\mathrm{G}$ cement of $\mathrm{w} / \mathrm{c}=0.4$ at a $25^{\circ} \mathrm{C}$ and $14.7 \mathrm{psi}$ and b $65^{\circ} \mathrm{C}$ and $300 \mathrm{psi}$
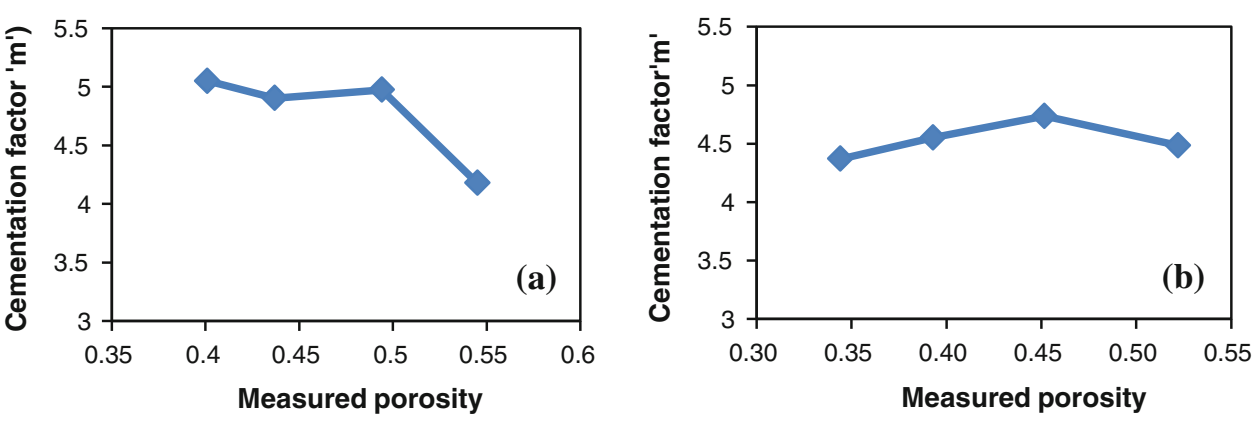

Fig. 7 Comparison of measured porosity and porosity predicted from Archie's equation of $\mathbf{a} \mathrm{w} / \mathrm{c}=0.5$, b $\mathrm{w} / \mathrm{c}=0.4$ and $\mathbf{c} \mathrm{w} / \mathrm{c}=0.3$
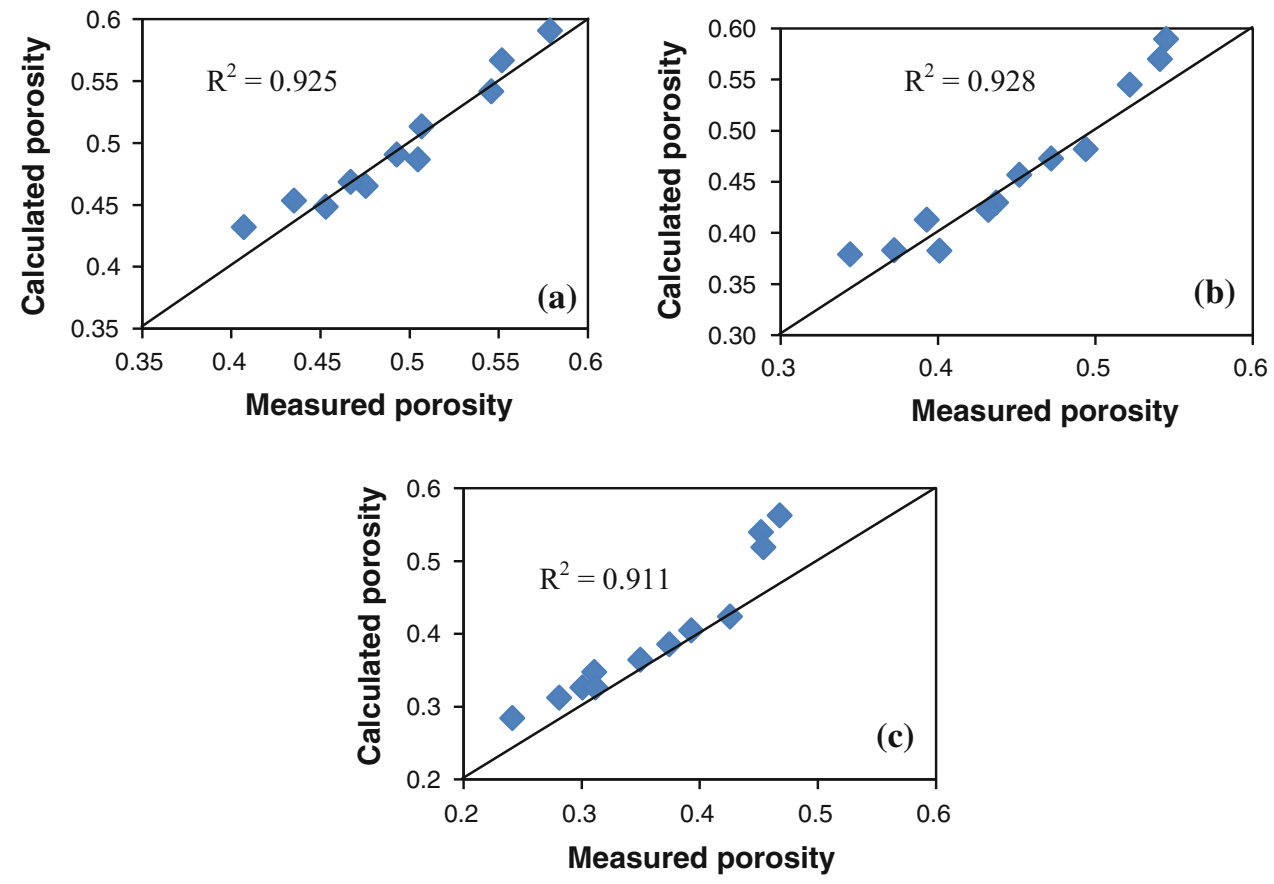

بونينة الملك عبدالعزيز 
was, the more tortuous the network would be. As the cement further hydrated, the connectivity became narrower and more tortuous as indicated by the microstructural parameter ( $m$ factor) changed with age. Accounting for these changes, a fitting procedure was performed on the models to the experimental measurements of electrical conductivity.

Figure 6 shows the microstructure parameters distribution from fitting procedure between Archie's model and experimental measurements. The downturn of the $m$ factor was observed-especially at elevated curing condition after cement was set. This was an artifact of the data approaching the percolation limit. The limit number proposed by Bentz and Garboczi (1991) was $\phi_{c}=0.18$ based on simulation. This turning point was early experienced at elevated curing conditions as an effect of hydration acceleration.

Comparisons of measured and calculated porosity are presented in Fig. 7. It can be seen that the Archie's equation overpredicted the porosity at the early ages for all w/c ratios. The relatively low overprediction occurred at the high w/c due to the chosen cementation factor that might have caused this behavior. The phenomena of overprediction seemed to appear due to the dominant effect of pore solution conductivity compared to that of porosity. On the other hand, as hydration product started to form and an opening pore diluted, the predictions seemed to agree well with the experimental values at the later ages. These values were used as an input for the strength estimation applied in the Hasselman model.
Fig. 8 Comparison of compressive strength predicted from the modified Hasselmann equation and measured compressive strength under different curing conditions $\mathbf{a} \mathrm{w} / \mathrm{c}=0.5, \mathbf{b} \mathrm{w} / \mathrm{c}=0.4$ and c $w / c=0.3$
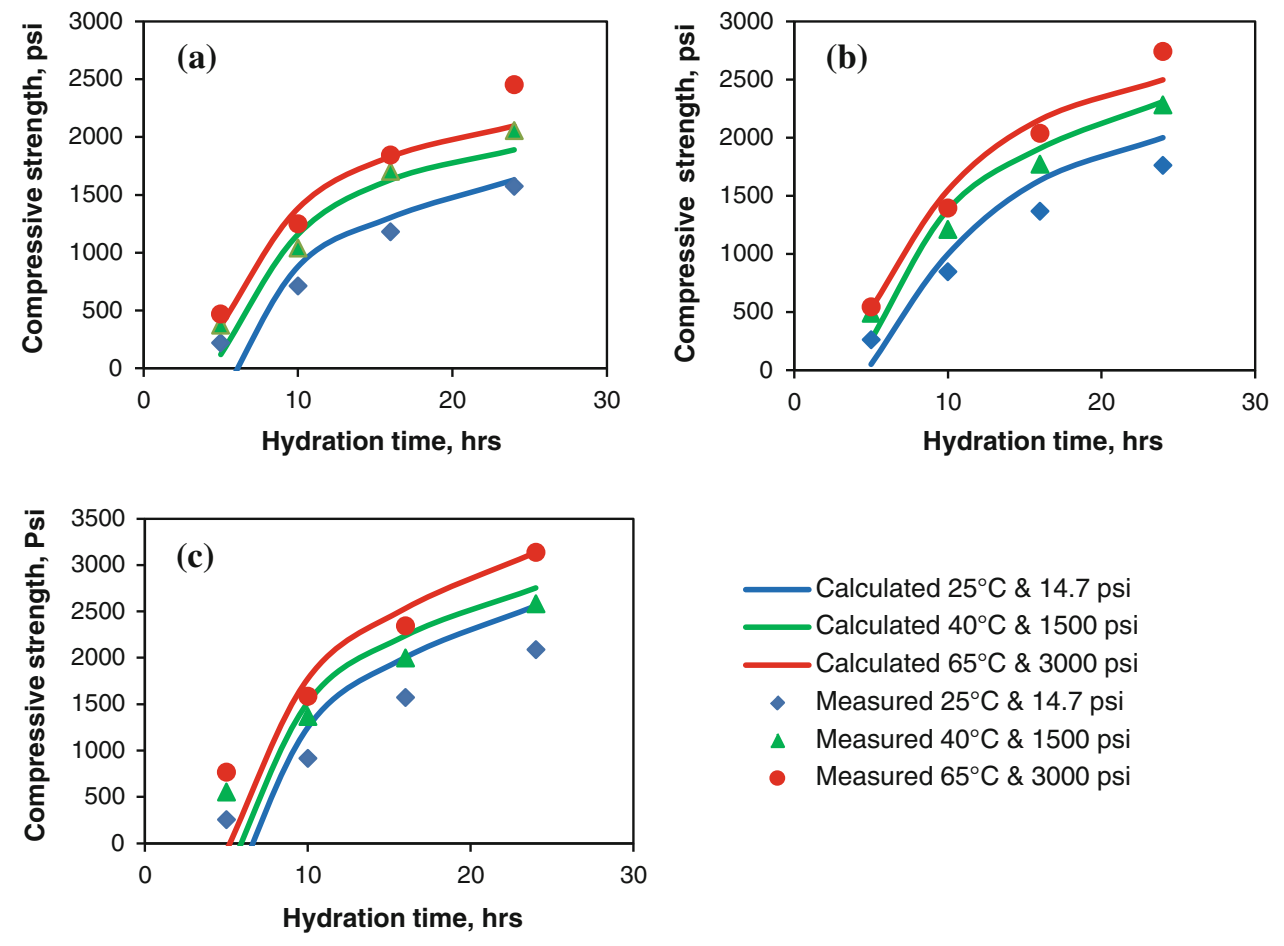

Fig. 9 Comparison of the measured and predicted strengths using the modified Hasselman equation at $70{ }^{\circ} \mathrm{C}$ and 3,000 psi for w/c a 0.25 and b 0.55
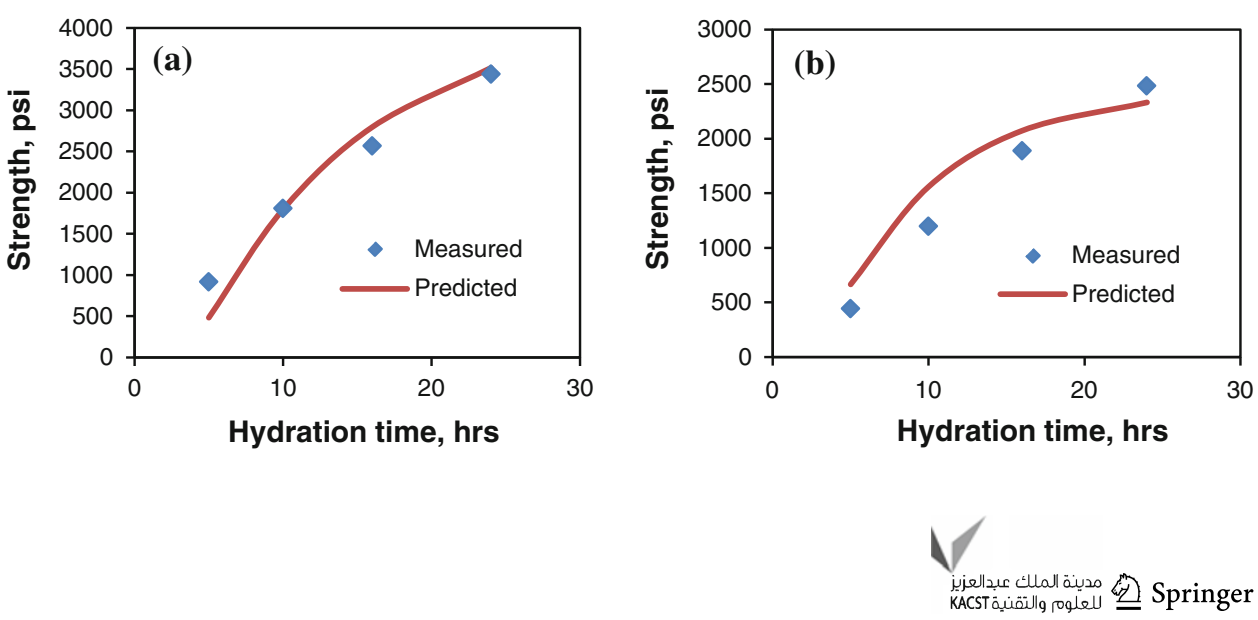
Empirical equation for strength prediction

From the values of porosities predicted using Archie's equation as described in the previous section, the strengths of Class $\mathrm{G}$ cement could be predicted using the modified model of Hasselman equation as follows:

$S=S_{0}-b\left(\frac{\sigma_{b}}{\sigma_{0}}\right)^{1 / m}$

where $S$ is the strength, $S_{o}$ the strength at zero porosity, $b$ the empirical constant, $\sigma_{b}$ the bulk conductivity, $\sigma_{o}$ the pore solution conductivity, and $m$ is the cementation factor.

Figure 8 shows the predicted strengths and the measured ones of the oilwell cement as a function of hydration time. The strength predicted using modified Hasselman equation showed a good agreement between the experimental data and predicted one with level of error below $19 \%$. It was satisfactory for all water to cement ratios with average coefficient of determination $\left(R^{2}\right)$ of 0.92 for $0.5 \mathrm{w} / \mathrm{c}, 0.95$ for $0.4 \mathrm{w} / \mathrm{c}$ and 0.90 for $0.3 \mathrm{w} / \mathrm{c}$. The values of the constants and cementation factors used in the Hasselman equation might be the reason for the slight discrepancy for each w/c ratios. However, it may give a practical way to estimate the strength development of well cement in-placed using its electrical properties data.

Equation (7), subsequently, was applied for the strength prediction of cement at different mixing and curing conditions at which samples with w/c 0.25 and w/c 0.55 were conditioned at $70{ }^{\circ} \mathrm{C}$ and 3,000 psi. The measured strength and prediction using Eq. (7) are exhibited in Fig. 9. The result shows a good agreement between the predicted and measured strengths with the level of error about below $15 \%$.

Moreover, Eq. (7) was also performed for these sample conditions with hydration period up to 50 days. The result of the measured and predicted strengths is given in Fig. 10. It can be seen that with 1 day electrical conductivity measurement, the error in estimating 50 days strength was

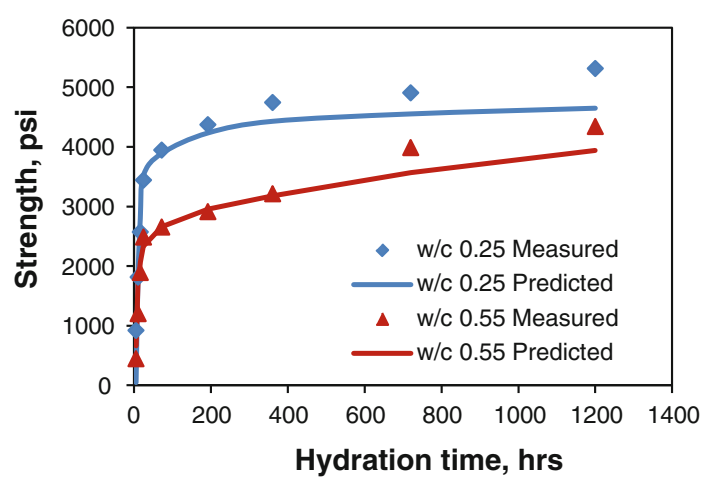

Fig. 10 Measured and predicted strengths of Class $\mathrm{G}$ cement sample at $70{ }^{\circ} \mathrm{C}$ and 3,000 psi up to 50 days $(1,200 \mathrm{~h})$ of hydration
$<31 \%$ and the error in estimating 15 days was $<18 \%$. The predicted strength above 15 days of hydration time seems to underestimate the measured value. It was suspected due to the selection of constant cementation factor instead of changing simultaneously as an effect of hydration mechanism and curing condition. It can be said that the measured conductivity data for 1 day can be used to predict the strength development up to 50 days with acceptable accuracy.

\section{Conclusion}

A good correlation was observed between porosity and strength in the form of power law. It was then used as a basis for strength prediction using electrical properties measurements. The porosity values for strength prediction were calculated using Archie's equation based on its electrical properties. The employment of electrical properties on the power law correlation resulted in the modified version of Hasselman equation. The correlation between measured strength and strength predicted using modified Hasselman equation was found to be satisfied. The predictive equation was also applicable for the new cement sample with different w/c and curing conditions up to 50 days of hydration period.

Acknowledgments This research was supported by the Department of Petroleum Engineering, Universiti Teknologi PETRONAS.

Open Access This article is distributed under the terms of the Creative Commons Attribution License which permits any use, distribution, and reproduction in any medium, provided the original author(s) and the source are credited.

\section{References}

API RP 10A. (2002). Specification for cements and materials for well cementing. 23rd edn

API RP 10B-2. (2005). Recommended practice for testing well cements. 1 st edn

Archie GE (1942) The electrical resistivity $\log$ as an aid in determining some reservoir characteristics petroleum. Trans AIME 146:54-62

Autolab-500 manual book. New England Research Inc, 2007

Backe KR, Lile OB, Lyomov SK (2001). Characterizing curing cement slurries by electrical conductivity. SPE paper 74694

Balshin MY (1949) Relation of mechanical properties of powder metals and their porosity and the ultimate properties of porous metal-ceramic materials. Dokl Akad Nauk SSSR 67(5):831-834

Bentz DP, Garboczi EJ (1991) Percolation of phases in a threedimensional cement phase microstructure model. Cem Concr Res 21(2-3):325-344

Christensen BJ, Coverdale RT, Rudolf A, Ford SJ, Garboczi EJ, Jennings HM, Mason TO (1994) Impedance spectroscopy of hydrating cement-based materials: measurement, interpretation, and application. J Am Ceram Soc 77(11):2789-2802 
Christensen BJ, Mason TO, Jennings HM (1996) Comparison of measured and calculated permeabilities for hardened cement pastes. Cem Concr Res 26(9):1325-1334

Ewing RP, Hunt AG (2006) Dependence of the electrical conductivity on saturation in real porous media. Vadose Zone J 5(2):731-741

Ford SJ, Mason TO, Christensen BJ, Coverdale RT, Jennings HM, Garboczi EJ (1995) Electrode configurations and impedance spectra of cement pastes. J Mater Sci 30(5):1217-1224

Glover P (2009) What is the cementation exponent? A new interpretation. Lead edge 28(1):82-85

Gu P, Xu Z, Xie P, Beaudoin JJ (1993) Application of A.C. impedance techniques in studies of porous cementitious materials (I). Influence of solid phase and pore solution on high frequency reristance. Cem Concr Res 23(3):531-540

Hasselman DPH, Fulrath RM (1964) Effect of small fraction of spherical porosity on elastic moduli of glass. J Am Ceram Soc 47:52-53

Justnes H, Skalle P, Sveen J, Oye BA (1995) Porosity of oil well cement slurries during setting. Adv Cem Res 7(25):9-12
Mindess S, Young JF, Darwin D (2003) Concrete. 2nd edn. 40(10). Prentice Hall, Englewood Cliffs, USA

Neithalath N, Persun J, Manchiryal RK (2011) Electrical conductivity based microstructure and strength prediction of plain and modified concretes. Int J Adv Eng Sci Appl Math 2(3):83-94

Rajabipour F, Weiss J (2007) Electrical conductivity of drying cement paste. Mater Struct 40(10):1143-1160

Ryshkewitch E (1953) Compression strength of porous sintered alumina and zirconia. J Am Ceram Soc 36:65-68

Schiller KK (1971) Strength of porous materials. Cem Concr Res 1(4):419-422

Washburn EW (1921) The dynamics of capillary flow. Phys Rev 17(3):273-283

Zhang J, Qin L, Li Z (2009) Hydration monitoring of cement-based materials with resistivity and ultrasonic methods. Mater Struct 42(1):15-24 